\title{
Primary Amenorrhea Accompanied by Adrenal Adenoma: Start of Menarche Soon after Tumor Resection
}

\author{
Yoshimi Takahashi, Jun Ninomiya*, Jun Horiguchi*, Hiroyuki Shimizu, Minoru Sato, Yukio Koibuchi*, \\ Takashi YoshidA*, Miho YoshidA*, Daisuke TAKatA*, Hiroki OdawArA*, Takao YoKoE**, \\ Yuichi IINO**, Yasuo MorishitA* and Masatomo MoRI
}

\begin{abstract}
We report a patient with primary amenorrhea accompanied by adrenal adenoma. A 21-year-old woman was admitted to our hospital because of primary amenorrhea and hyperprogesteronemia without virilization. Venous sampling showed progesterone overproduction at the left adrenal gland. Computed tomography revealed a $7 \mathrm{~cm}$ mass in left adrenal gland. Serum pregnenorone, 17-hydroxypregnenorone, dehydroepiandrosterone, 17-hydroxyprogesterone, deoxycorticosterone, and 11-deoxycortisol were elevated. The diagnosis of steroid hormone producing tumor was made. Following tumor resection, serum progesterone normalized 4 days later, and menarche occurred 51 days after operation. The present case indicated that adrenal functioning tumor should not be overlooked in patients with primary amenorrhea.
\end{abstract}

(Internal Medicine 41: 972-976, 2002)

Key words: primary amenorrhea, progesterone, adrenal adenoma

\section{Introduction}

The frequency of incidental detection of adrenal tumors has been recently increasing due to advances in radiological imaging techniques. Tumors of adrenal gland sometimes produce various kinds of steroid hormones, such as cortisol, aldosterone, and androgens. However, a testosterone or estrogen producing adrenal tumor is very rare (1). To our knowledge, there is only one report of primary amenorrhea due to an adrenal tumor which produced progesterone (2).

Various causes of primary amenorrhea have been reported (3). The progestins, progesterone and 17-hydroxyprogesterone, act by altering estrogen receptors and/or hastening estradiol metabolism at the target organ level. Amenorrhea in the patients with congenital adrenal hyperplasia has been attributed to high progestogenic steroids levels exerting a "mini-pill" effect on the endometrium (4). But the role of progestins has not been well established in the pathogenesis of primary amenorrhea which is caused by various kinds of pathogenesis.

We encountered a case of primary amenorrhea accompanied by adrenal adenoma which produced progesterone and related adrenal steroid hormones. Resection of the adrenal tumor almost normalized the serum concentrations of progesterone and related adrenal steroids, and menarche occurred 51 days later.

For editorial comment, see p 912.

\section{Case Report}

A 21-year-old woman was admitted to our hospital in March 2001 , because of primary amenorrhea and hyperprogesteronemia. She had visited a gynecologist because of primary amenorrhea at age of 18-years. On physical examination, there was no clinical evidence of virilization or hypercortisolism. Slight atrophy of uterus and ovaries was pointed out by the gynecologist. Plasma progesterone concentration was elevated $(13.4 \mathrm{ng} / \mathrm{ml}$; normal range: $<0.7)$, but other endocrinological data measured by the gynecologist were normal. Various ovarian stimulation therapies by estrogen and gonadotropin releasing hormone analogue were performed from July 1999 to November 2000, but menarche did not occur and plasma progesterone remained at high concentrations. Then, selective venous sampling was performed to determine a site of progesterone overproduction. In this study, the progesterone concentration from the left adrenal vein was 1.45 times higher than right adrenal vein (right adrenal vein: $6.5 \mathrm{ng} / \mathrm{ml}$, left adrenal vein: 9.4 $\mathrm{ng} / \mathrm{ml}$ ). Computed tomography of the abdomen revealed a $7 \times 6$ $\mathrm{cm}$ mass in left adrenal gland (Fig. 1A). Then, we considered

From the First Department of Internal Medicine, *the Second Deaprtment of Surgery and **Department of Emergency and Critical Care, Gunma University School of Medicine, Maebashi

Received for publication April 17, 2002; Accepted for publication July 9, 2002

Reprint requests should be addressed to Dr. Yoshimi Takahashi, the First Department of Internal Medicine, Gunma University School of Medicine, 3-39-15 Showa-machi, Maebashi, Gunma 371-8511 


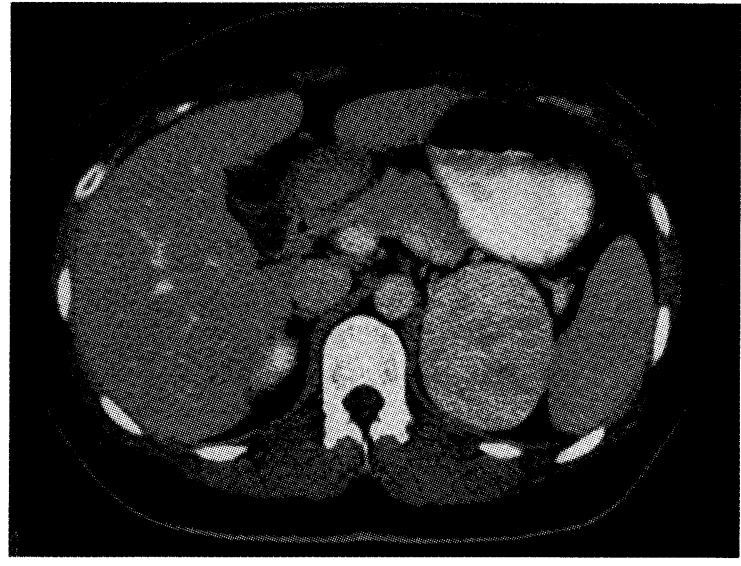

A

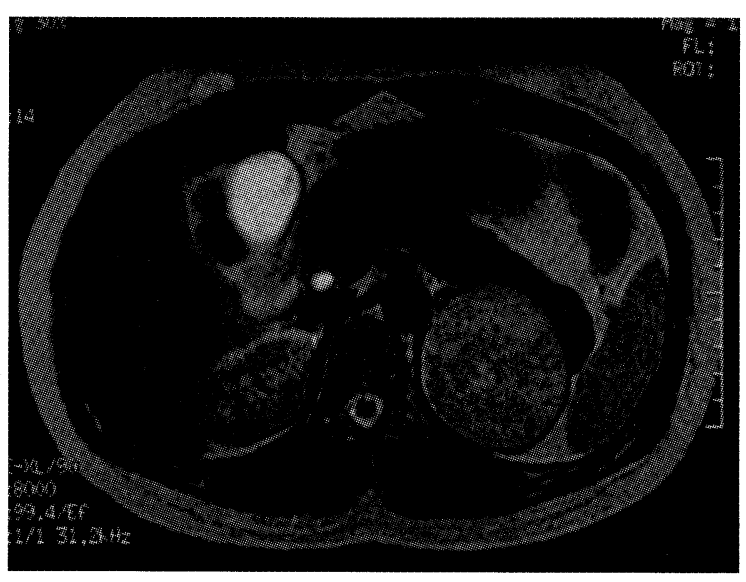

B

Figure 1. A; Abdominal CT scan, B; abdominal MRI.

Table 1. Endocrinological Findings on Admission

\begin{tabular}{|c|c|c|c|c|c|c|c|}
\hline \multicolumn{7}{|c|}{ Normal range } & \multirow{2}{*}{$\frac{\text { Normal range }}{(2.2-7.3)}$} \\
\hline GH & $<0.3 \mathrm{ng} / \mathrm{ml}$ & $(1.0-5.7)$ & \multicolumn{2}{|c|}{$\mathrm{u}-17 \mathrm{OHCS}$} & \multicolumn{2}{|c|}{$14.0 \mathrm{mg} / \mathrm{day}$} & \\
\hline ACTH & $27 \mathrm{pg} / \mathrm{ml}$ & $(9.0-52.0)$ & \multicolumn{2}{|c|}{$\mathrm{u}-17 \mathrm{KS}$} & \multicolumn{2}{|c|}{$15.0 \mathrm{mg} /$ day } & $(2.4-11.0)$ \\
\hline LH & $2.9 \mu \mathrm{U} / \mathrm{ml}$ & $(* 1)$ & \multicolumn{2}{|c|}{$\mathrm{u}$-free cortisol } & \multicolumn{2}{|c|}{$140 \mu \mathrm{g} /$ day } & $(35.0-160.0)$ \\
\hline FSH & $4.5 \mu \mathrm{U} / \mathrm{ml}$ & $(* 2)$ & \multicolumn{2}{|c|}{ u-pregnandiol } & \multicolumn{2}{|c|}{$13.1 \mathrm{mg} /$ day } & $(* 3)$ \\
\hline PRL & $4.3 \mathrm{ng} / \mathrm{ml}$ & $(1.9-13.2)$ & \multicolumn{2}{|c|}{ u-pregnantriol } & \multicolumn{2}{|c|}{$8.53 \mathrm{mg} /$ day } & $(* 4)$ \\
\hline TSH & $0.89 \mu \mathrm{U} / \mathrm{ml}$ & $(0.5-5.5)$ & \multicolumn{2}{|c|}{ u-metanephrine } & \multicolumn{2}{|c|}{$0.05 \mathrm{mg} /$ day } & $(0.04-0.18)$ \\
\hline f-T3 & $1.9 \mathrm{pg} / \mathrm{ml}$ & $(2.4-4.5)$ & \multicolumn{2}{|c|}{ u-normetanephrin } & \multicolumn{2}{|c|}{$0.09 \mathrm{mg} /$ day } & $(0.10-0.28)$ \\
\hline $\mathrm{f}-\mathrm{T} 4$ & $1.0 \mathrm{ng} / \mathrm{dl}$ & $(0.8-2.1)$ & \multicolumn{2}{|c|}{ u-adrenaline } & \multicolumn{2}{|c|}{$4.0 \mu \mathrm{g} / \mathrm{day}$} & $(3.0-41.0)$ \\
\hline thyroglobulin & $6.7 \mathrm{ng} / \mathrm{ml}$ & $(<30.0)$ & \multicolumn{2}{|c|}{ u-noradrenaline } & \multicolumn{2}{|c|}{$40.0 \mu \mathrm{g} /$ day } & $(31.0-160.0)$ \\
\hline anti-thyroid $\mathrm{Ab}$ & $<100 \times$ & & \multicolumn{2}{|c|}{ u-dopamine } & \multicolumn{2}{|c|}{$605.3 \mu \mathrm{g} /$ day } & $(280.0-1100.0)$ \\
\hline anti-microsome $\mathrm{Ab}$ & $<100 \times$ & & \multicolumn{2}{|c|}{$\mathrm{u}-\mathrm{Na}$} & \multicolumn{2}{|c|}{$185 \mathrm{mEq} / l$} & \\
\hline cortisol & $12.8 \mu \mathrm{g} / \mathrm{dl}$ & $(7.0-25.0)$ & & Follicular & & Luteal & \\
\hline plasma renin activity & $0.3 \mathrm{ng} / \mathrm{ml} / \mathrm{h}$ & $(0.3-2.9)$ & & phase & Ovulation & phase & Menopause \\
\hline aldosterone & $110 \mathrm{pg} / \mathrm{ml}$ & $(29.9-159.0)$ & & & & & \\
\hline adrenaline & $0.02 \mathrm{ng} / \mathrm{ml}$ & $(<0.10)$ & $* 1$ & $1.1-24.0$ & $7.1-274.2$ & $0.4-56.0$ & $7.3-81.2$ \\
\hline noradrenaline & $0.39 \mathrm{ng} / \mathrm{ml}$ & $(0.1-0.5)$ & $* 2$ & $2.2-42.7$ & $4.4-64.2$ & $0.6-25.9$ & $7.7-479.0$ \\
\hline dopamine & $0.01 \mathrm{ng} / \mathrm{ml}$ & $(<0.03)$ & $* 3$ & $0.2-1.3$ & - & $0.7-4.7$ & $<1.0$ \\
\hline & & & $* 4$ & $0.1-1.3$ & - & $0.2-1.6$ & $<1.0$ \\
\hline
\end{tabular}

that primary amenorrhea was caused by a progesterone producing adrenal tumor. She had no particular family histories of endocrine tumors. She also had no past history.

On admission, height was $152.8 \mathrm{~cm}$, body weight $60.5 \mathrm{~kg}$, body temperature $36.2^{\circ} \mathrm{C}$, blood pressure $129 / 91 \mathrm{mmHg}$ and heart rate $52 / \mathrm{min}$. There were no abnormal physical findings including alopecia. On gynecological examination, slightly atrophic uterus and ovaries were found. Her basal body temperature had no biphasic pattern and continued to be high.

There were no abnormal findings on hematological, biochemical data, serological data and urinalysis (data not shown). Endocrinological data were shown in Table 1. Plasma proges- terone concentration was remarkably high $(8.6 \mathrm{ng} / \mathrm{ml})$, and serum concentration of pregnenorone $(3.51 \mathrm{ng} / \mathrm{ml}$; normal range: 0.2-1.5), 17-hydroxypregnenorone ( $49.50 \mathrm{ng} / \mathrm{ml}$; normal range: 0.2-1.5), dehydroepiandrosterone (DHEA; $10.30 \mathrm{ng} / \mathrm{ml}$; normal range: $2.02-8.03)$, 17-hydroxyprogesterone $(3.5 \mathrm{ng} / \mathrm{ml}$; normal range: $0.1-3.3$ ), deoxycorticosterone (DOC; $0.78 \mathrm{ng} /$ $\mathrm{ml}$; normal range: $0.03-0.33), 11$-deoxycortisol $(8.56 \mathrm{ng} / \mathrm{ml}$; normal range: $0.11-0.60$ ) were also elevated (Fig. 2A). However, diurnal rhythmicity of plasma adrenocorticotoropin (ACTH) and serum cortisol concentrations remained normal. Serum cortisol was suppressed by $1 \mathrm{mg}$ dexamethasone, but plasma progesterone was not suppressed. The response of se- 


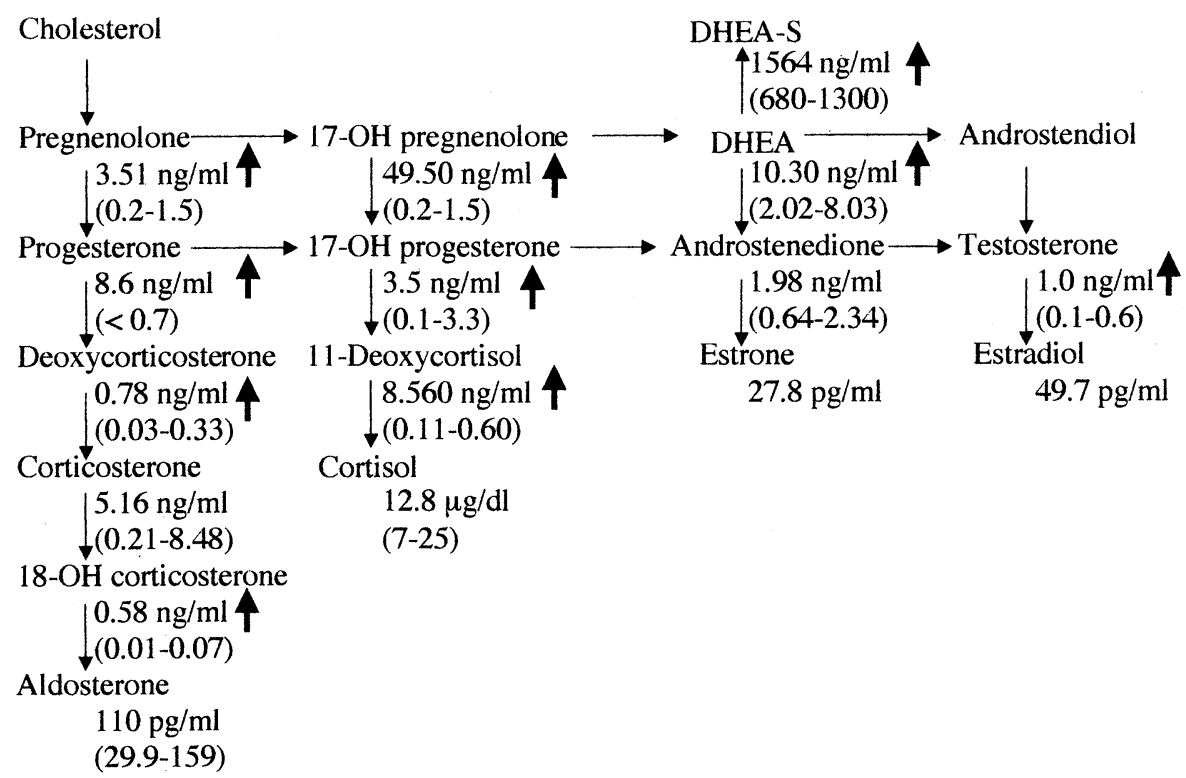

A

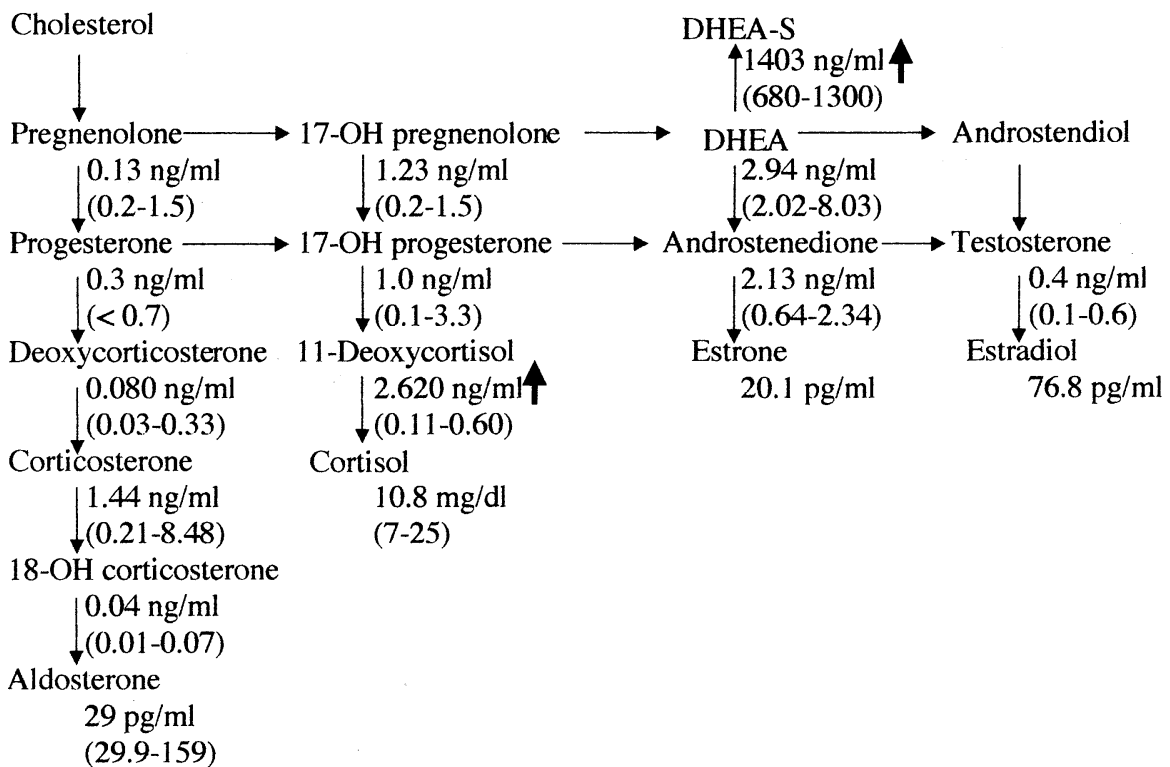

Figure 2. Circulating levels of adrenal steroid hormones before (A) and after (B) the resection of adrenal tumor.

rum cortisol to intravenous administration of synthetic 1-24 ACTH was normal. Plasma progesterone and 17 hydroxyprogesterone were not increased by ACTH administration. Luteinizing hormone $(\mathrm{LH})$ and follicle stimulating hormone (FSH) showed a normal response to intravenous administration of luteinizing hormone-releasing hormone (LH-RH). In addition, magnetic resonance imaging (MRI) revealed a low intensity tumor on $\mathrm{T} 1$ emphasizing phase and high intensity tumor on $\mathrm{T} 2$, without any finding to suggest invasion or adhesion to surrounding organs in the frontal view (Fig. 1B). Scintigraphy using 131-I showed almost the same accumulation in the bilateral adrenal gland. These results excluded the existence of preclinical Cushing syndrome and congenital adrenal enzyme deficiency.

Under the diagnosis of adrenal tumor which produced progesterone and related adrenal steroids, the tumor was 

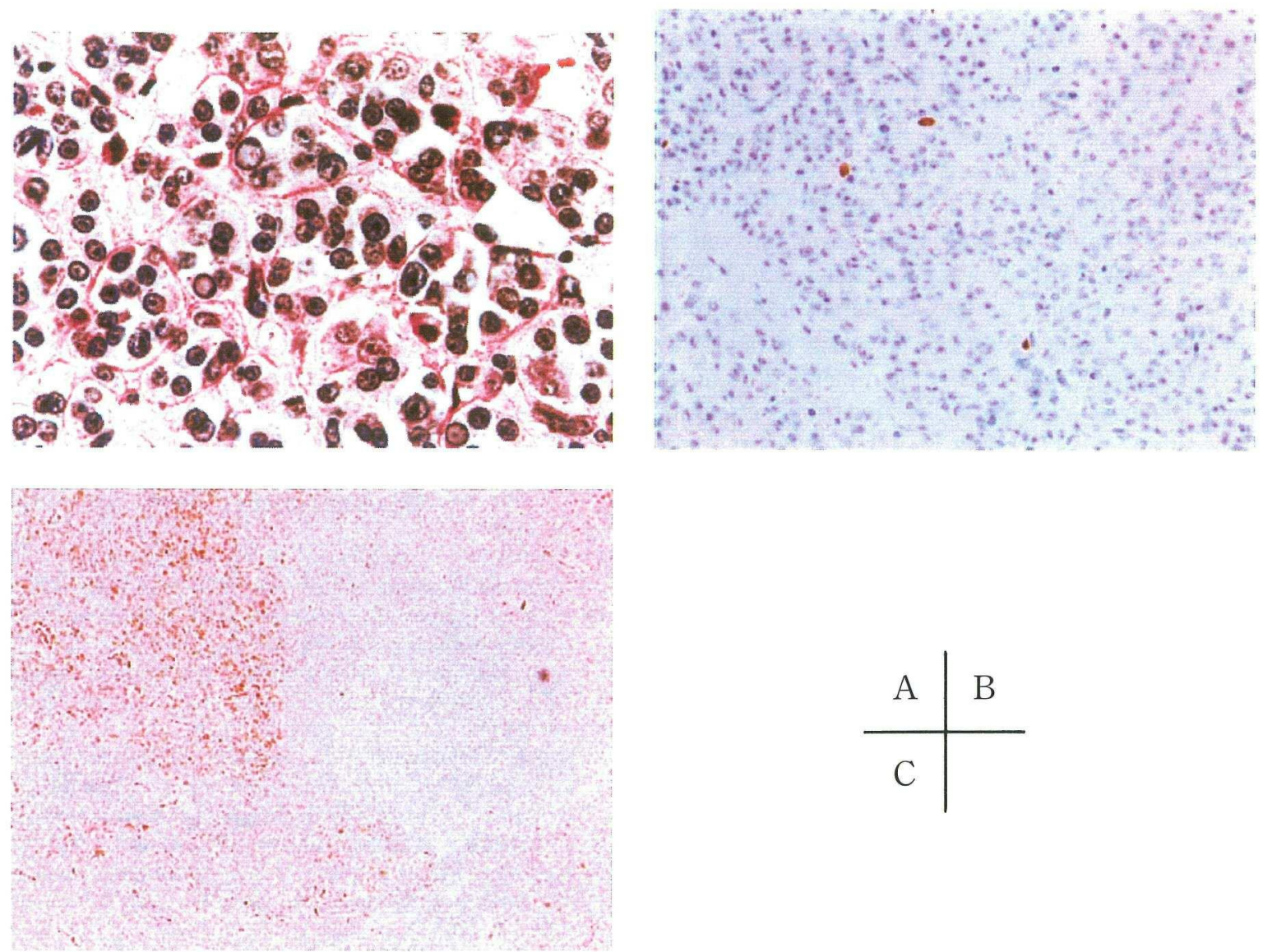

Figure 3. Microscopic and immunohistochemical finding of resected adrenal tumor. A; hematoxylin-eosin staining ( $\times 400)$, B: immunohistochemical staining using Ki-67 antibody (MIB-1), C: immunohistochemical staining using vimentin.

resected through a posterolateral skin incision. The tumor was $8.0 \times 6.0 \times 5.6 \mathrm{~cm}$ in size and weighed $110 \mathrm{~g}$. The cut surface of the tumor was dark-brown color, solid, and homogenous. Pathological examination demonstrated that main composition of the tumor was various sized cells with eosinophilic granules and polymorphic nuclei (Fig. 3A). There was no evidence of venous invasion, or sinusoidal invasion. The tumor contained $480 \mathrm{pmol} /$ wet $g$ of progesterone.

Following the operation, the serum progesterone concentration was normalized at $0.8 \mathrm{ng} / \mathrm{ml}$ at 4 days, and the serum estradiol concentration was also increased. Two weeks later, her basal body temperature went down and became biphasic. Menarche occurred 51 days after the operation.

\section{Discussion}

We report here a patient of primary amenorrhea with hyperprogesteronemia accompanied by adrenal tumor. We presumed that the left adrenal tumor produced progesterone and the related adrenal steroid hormones, resulting in primary amenorrhea. After resection of the left adrenal tumor, the serum progesterone concentration was immediately normalized, and menarche occurred 51 days after the operation.

A connection between amenorrhea and progesterone has been reported in congenital adrenal hyperplasia (5). The primary amenorrhea was the result of autonomous overproduction of progesterone which might reduce LH and FSH secretion. The progestins accumulate immediately behind the enzyme block in 21-hydroxylase deficiency. Congenital adrenal hyperplasia characterized by 21-hydroxylase deficiency or 17 hydroxylase deficiency often increases the plasma progesterone concentration (6). In the present case, several examinations before the operation excluded preclinical Cushing syndrome and congenital adrenal hyperplasia. Circulating concentrations of adrenal steroids were normalized by tumor resection, except for dehydroepiandrosterone-sulfate (DHEA-S) and 11-deoxycortisol, indicating the strong involvement of adrenal adenoma in primary amenorrhea. Although the serum DHEA$S$ level still remained high after the resection of adrenal adenoma, gynecological study showed the existence of polycystic ovary and that the ratio of serum $\mathrm{LH}(6.0 \mu \mathrm{U} / \mathrm{ml})$ to FSH $(5.9 \mu \mathrm{U} / \mathrm{ml})$ was increased over 1.0 after the operation. The 
possible complication of polycystic ovary syndrome can explain the high level of DHEA-S after the operation.

Increased secretion of 17-hydroxyprogesterone after stimulation with ACTH has been described in $30-71 \%$ of adrenal "incidentaloma", suggesting a defect in the 21-hydroxylase gene $(7,8)$. An exaggerated response of 17-hydroxyprogesterone to ACTH may be due to mild 21-hydroxylase deficiency (9) or may be caused by other abnormalities of steroid biosynthesis in these tumors, such as $11 \beta$-hydroxylase deficiency (10). The ratio of 11-deoxycortisol to cortisol is higher in $40 \%$ of patients with adrenal "incidentalomas", and these patients have increased responses of precursors of the mineralcorticoid and glucocorticoid pathway including 17-hydroxyprogesterone after stimulation with ACTH (11). This may be caused by impairment of $11 \beta$-hydroxylase activity rather than by impaired 21 hydroxylase activity (11). In the present case, the increased ratio of 11-deoxycortisol to cortisol $(19.2 / 173.8=0.11)$ and an obvious reduction of the ratio after adrenal tumor resection $(11.1 / 480=0.02)$ may suggest the existence of impairment of $11 \beta$-hydroxylase activity in resected adrenal adenoma [controls; 0.005 from data of Reincke et al (11)].

Some estradiol, androgen or testosterone producing adrenal tumors have been reported $(1,12-17)$. However, a progesterone producing adrenal tumor is quite rare. Only one case has been reported to date (2). Estradiol or androgen producing tumors have a high frequency of malignancy $(1,12,17)$. Significantly higher baseline 11-deoxycortisol/cortisol and 11-deoxycorticosterone/corticosterone ratios, which were normalized after adrenalectomy, have been demonstrated in adrenocortical carcinomas (18). Pathological examination did not show any malignant histology at all in the present case. Pathological observation of progesterone-producing adrenal adenoma reported by van Zonneveld et al demonstrated that the tumor was predominantly composed of clear cells with hemorrhage and necrosis (2). In contrast, in the present case, the tumor was composed dominantly of compact cells without any necrosis and hemorrhage. Therefore, the pathological characteristics of the tumor in this case appears to be quite different from the previous case. However, a MIB-1 labeling index correlating with the mitotic index $(1.8 \%)$ in the present patient was the same as that in the previously reported case (Fig. 3B) and immunohistochemical staining using vimentin showed heterogenous staining (Fig. 3C). No malignancy was indicated from the pathological observations in the two cases. To explain these differences in the pathological observations, accumulation of similar cases of progesterone-producing adrenal adenoma is necessary in the future.

It is concluded that primary amenorrhea may be caused by adrenal adenoma which produces progesterone and related adrenal steroids. The existence of adrenal adenoma which produces sex steroids should not be overlooked in the differential diagnosis of primary amenorrhea.

\section{Reference}

1) Kamilaris TC, DeBold CR, Manolas KJ, Hoursanidis A, Panageas $S$, Yiannatos J. Testosterone-secreting adrenal adenoma in a peripubertal girl. JAMA 258: 2558-2561, 1987.

2) van Zonneveld P, Koppeschaar HP, de Bruin TW, Vroom TM, Blankenstein MA, van Vroonhoven TJ. A patient with a progesterone-producing adrenal adenoma who presented with primary amenorrhea. Gynecol Endocrinol 9: 189-194, 1995.

3) Mashchak CA, Kletzky OA, Davajan V, Mishell DR. Clinical and laboratory evaluation of patients with primary amenorrhea. Obstet Gynecol 57: 715-721, 1981.

4) Helleday J, Siwers, Ritzen EM, Carlstrom K. Subnormal androgen and elevated progesterone levels in women treated for congenital virilizing 21-hydroxylase deficiency. J Clin Endocrinol Metab 76: 933-936, 1993.

5) Rosenfield RL, Bickel $S$, Razdan AK. Amenorrhea related to progestin excess in congenital adrenal hyperplasia. Obstet and Gynecology 56: 208$215,1980$.

6) Holmes-walker DJ, Conway GS, Honour JW, Rumsby G, Jacobs HS. Menstrual disturbance and hypersecretion of progesterone in women with congenital adrenal hyperplasia due to 21-hydroxylase deficiency. Clin Endocrinol 43: 291-296, 1995.

7) Terzolo M, Osella G, Ali A, et al. Different patterns of steroid secretion in patients with adrenal incidentalomas. J Clin Endocrinol Metab 81: 740744, 1996.

8) Seppel T, Schlaghecke R. Augmented 17-alpha-hydroxyprogesterone response to ACTH stimulation as evidence of decreased 21-hydroxylase activity in patients with incidentally discovered adrenal tumors ('incidentalomas'). Clin Endocrinol (Oxf) 41: 445-451, 1994.

9) New MI, Lorenzen F, Lerner AJ, et al. Genotyping steroid 21-hydroxylase deficiency: Hormonal reference data. J Clin Endocrinol Metab 57: 320-326, 1983.

10) Eldar-Geva T, Hurwitz A, Vecsei P, Palti Z, Milwidsky A, Rösler A. Secondary biosynthetic defects in women with late-onset congenital adrenal hyperplasia. New Engl J Med 323: 855-863, 1990.

11) Reincke M, Peter M, Sippell WG, Allolio B. Impairment of 11b-hydroxylase but not 21-hydroxylase in adrenal "incidentalomas". Eur J Endocrinol 136: 196-200, 1997.

12) Gabrilove JL, Sharma DC, Wotiz HH, Dorfman RI. Feminizing adrenocortical tumors in the male. Medicine 44: 37-79, 1965.

13) Mersey JH, Ceballos L, Levin P, Busky S. Estrogen-secreting adrenal tumor responsive to ACTH: Localization by adrenal venous sampling. South Med J 81: 275-278, 1988.

14) Saadi HF, Bravo EL, Aron DC. Feminizing adrenocortical tumor: Steroid hormone response to ketoconazole. J Clin Endocrinol Metab 70: 540543, 1990.

15) McKenna TJ, O'Connell Y, Cunningham S, McCabe M, Culliton M. Steroidogenesis in estrogen-producing adrenal tumor in a young woman: Comparison with steroid profiles associated with cortisol and androgen producing tumors. J Endocrinol Metab 70: 28-34, 1990.

16) Gabrilove JL, Seman AT, Sabet R, Mitty HA, Nicolis GL. Virilizing adrenal adenoma with studies on the steroid content of the adrenal venous effluent and a review of the literature. Endocr Rev 2: 462-470, 1981.

17) Del Gaudio AD, Del Gaudio GA. Virilizing adrenocortical tumors in adult women. Cancer 72: 1997-2003, 1993.

18) Döerr HG, Sippell WG, Drop SL, Bidlingmaier F, Knorr D. Evidence of 11-beta -hydroxylase deficiency in childhood adrenocortical tumors. The plasma corticosterone/11-deoxycorticosterone ratio as a possible marker for malignancy. Cancer 60: 1625-1629, 1987. 